\title{
Energy Efficiency with Undesirable Output at the Economy-Wide Level: Cross Country Comparison in OECD Sample
}

\author{
Nevzat Simsek ${ }^{*}$ \\ Department of Economics, Dokuz Eylul University, Izmir, Turkey and Department of Economics, Hoca Ahmet Yesevi International \\ Turkish-Kazakh University, Turkestan, Kazakhstan \\ *Corresponding author: nevzat.simsek@deu.edu.tr
}

Received January 04, 2014; Revised February 14, 2014; Accepted February 16, 2014

\begin{abstract}
Measuring the environmental efficiency of countries is important in the climate change process. The aim of this paper is to measure the energy efficiency of OECD countries with undesirable output. For this purpose, the Bad Output index (non-radial and non-oriented, CRS) developed by Tone (2001) is used in order to obtain the efficiency scores for the period 1995-2009. In this paper, I focus on the production process where labour, capital stock (mostly omitted in such papers), and energy consumption are inputs, GDP is a desirable output and $\mathrm{CO}_{2}$ emission is an undesirable output. To see the energy inefficiencies separately, if there are any, energy input is considered as three separate variables in the model. For this purpose, oil and natural gas consumption are incorporated as one input. Hydropower and nuclear are incorporated as another input. Coal is the third input. An important contribution of this paper is to use various proxy variables for the capital stock. Determining the reasons of these inefficiencies is important for these countries. But modelling the factors behind these inefficiencies is the subject of another paper.
\end{abstract}

Keywords: energy efficiency, environmental efficiency, Bad Output model, DEA, climate change, sustainable development

Cite This Article: Nevzat Simsek, "Energy Efficiency with Undesirable Output at the Economy-Wide Level: Cross Country Comparison in OECD Sample.” American Journal of Energy Research, vol. 2, no. 1 (2014): 9-17. doi: 10.12691/ajer-2-1-2.

\section{Introduction}

Energy is closely related to policy making discussions because of its importance to the social, economic and environmental development of many countries. Two issues seem to define the current debate on energy markets and policy. Firstly, the world depends to a great extent on a limited number of countries for their supply of fossil fuels. Energy usage is very important in every phase of a country's economic development. In the past the dependency of industries on oil in national economies was high due to its being relatively cheap. The 1970s energy crisis caused by the sharp hike in oil prices led to serious problems for both developed and developing countries. After the 1970s oil crisis, the energy problem, and especially the relationship between supply and demand, began to come to the fore for policy-makers. In the 1970s and early 1980s, energy efficiency, which can be achieved either by decreasing total energy use or increasing production rate per unit of energy consumed, was considered to be one of the major components of energy policies in the countries for reasons of security of supply, and as a way of returning to some kind of economic optimality. Improving energy efficiency will enhance the energy security of countries.

Secondly, the large amount of climate gas emissions by developed and developing countries seriously threatens the climate. Especially in the early 1990s, major environmental concerns arose, regarding the greenhouse effect that was strongly related to fossil fuel combustion, which gave new impetus to the improvement in energy efficiency (Bosseboeuf et al., 1997, Phylipsen et al., 2002, Grösche, 2008). It is obvious that combating climate change requires the international community to work together to reduce the total amount of $\mathrm{CO}_{2}$ emissions globally, ultimately stabilizing its atmospheric concentration at a level that would prevent dangerous anthropogenic interference with the climate system. At the third conference in Kyoto in 1997, legally binding emission reduction targets were determined for Annex-I countries (OECD countries and the countries of Eastern Europe and the former Soviet Union). But the concept of the Clean Development Mechanism in the Kyoto Protocol is implicitly based on this assumption: Developing countries are not very energy-efficient, and cheap emission reduction options can be found in those countries (Phylipsen et al., 2002). That is why improving energy efficiency in these countries is thought to be an important option for limiting energy-related greenhouse gas emissions, especially in the fast-growing industry sectors ${ }^{1}$ (Stern, 2007).

Over the last few years there has been an increasing need to provide governments with useful information to assist them in

\footnotetext{
${ }^{1}$ See also Price et al., 2000a and Price et al., 2000b for details.
} 
forming concrete policies to improve energy efficiency, and in taking measures to reduce emissions of $\mathrm{CO}_{2}$ and other greenhouse gases in the current negotiations within the United Nations Framework Convention on Climate Change. These kinds of studies could be useful in forming public policies that aim to reduce energy consumption and mitigate pollution. But there are still some unsolved issues in this area. The foremost issue in the measurement of energy efficiency performance is to define the term energy efficiency. To conceptualise the energy efficiency is difficult and there is no single commonly accepted definition. An engineer, an economist, and an environmentalist, for example, may each have a different concept of energy efficiency ${ }^{2}$. It is possible to identify in this literature two concepts that are used to analyze the relationship between energy usage and economic output: energy intensity and energy efficiency. It can be generally said that the less energy that is required to produce a unit of output, the greater is the efficiency and the lower the intensity (Mukherjee, 2008). As stated by Freeman et al. (1997) energy intensity indicators that are widely used in the literature should not be viewed as an exact indicator of energy efficiency. This is because changes in intensity indicators can be attributed to many changes such as behavioural, technological, efficiency or structural changes. That is, the energy intensity of GDP seems to be highly variable among different countries and periods ${ }^{3}$. Three main factors influence the level of energy consumption in an economy: the level of overall activity or production, the output or activity per unit of energy consumed, and the composition or structure of the economy. So the change in total energy consumption between two periods of time can be broken down into these three separate components: (i) the output/activity effect (change in the production level), (ii) the 'pure' energy intensity effect (accounting for change in technology, fuel shift/mix in the industries), and (iii) the structural effect (share of value of output change across the sector within a given time) (Azadeh et al., 2008; Reddy and Ray, 2010). Also the spectrum of indicators ranges from the simple ratio of energy usage per capita to sophisticated composite index approaches. These different definition and indicators can lead to different results and have different policy implications.

More importantly, most traditional energy intensity/ efficiency indicators consider only energy inputs in energy efficiency assessment. In recent years, many theoretical papers and empirical research in the literature have concluded that it is appropriate to have energy as an input in production analysis with other non-energy inputs such as capital and labour. Energy must be combined with non-energy inputs to produce output, because changes in non-energy inputs may impact upon energy efficiency. Therefore, the consideration of energy and non-energy inputs together would be appropriate in assessing energy efficiency. As a result of these considerations, data envelopment analysis (DEA) has gained in popularity in energy efficiency studies because of enabling energy as an input within a production framework where both energy and other non-energy inputs are used to produce desirable (good) outputs. In recent years, efficiency of countries is tried to

\footnotetext{
${ }^{2}$ In fact many national energy agencies, international organizations and researchers have developed their energy efficiency measurement to monitor economy-wide energy efficiency trends, or to compare energy efficiency performance across countries. See Patterson (1996), Ang (2006), Azadeh et al. (2008) and Zhou and Ang (2008) for a recent review.

${ }^{3}$ Many studies have been made to analyse international differences and the evolution of energy intensity inequalities. It can be found a good review in Duro et al. (2010).
}

measure by this nonparametric method. But it is really difficult to find relevant proxy for capital stock in deciding to use this method. There are some papers using the capital stock data, but data used in most of them end in the early 2000s, because data of recent capital stock (after 2000) are not available in any statistical yearbook or database. An important contribution of this paper is to use various proxy variables for the capital stock.

Because energy usage also results in the revealing of some undesirable (bad) outputs, such as $\mathrm{CO}_{2}$ emissions, as byproducts of producing desirable (good) outputs, the measurement of energy efficiency without considering these undesirable outputs does not seem to provide an equitable score for energy efficiency benchmarking and comparisons. But the traditional energy intensity/efficiency indicators don't take these undesirable outputs into consideration. Although there is continuing interest among academics and policy makers, there have been few in-depth examinations of economy-wide carbon performance. Several indicators such as energy intensity (energy/GDP), carbon intensity (carbon/GDP) and carbon factor (carbon/energy) are widely used to monitor a country or a region's performance in $\mathrm{CO}_{2}$ emissions over time. Currently, the most commonly used measure is carbon intensity. But, as stated by Yang (2010), this has many limitations. The carbon intensity is not only incapable of capturing multidimensional features of an economy's carbon performance but also of measuring the substitution effects between energy and non-energy inputs. For example, the carbon intensity of an economy may increase solely because energy is replacing labour, rather than due to any underlying deterioration in emitting technology. It would therefore be appropriate to evaluate the economic-wide energy efficiencies within a joint production framework. In this framework, desirable (good) and undesirable (bad) outputs should be considered simultaneously.

In the DEA literature, several authors have proposed methods based on adjustments of conventional measures of efficiency in an environmental efficiency measurement. In this paper, as compared to other papers, not only capital stock but also bad output is included in the model. To sum up, this paper uses the DEA approach as compared to the traditional indicators, because of two major advantages. Firstly, DEA accommodates multiple inputs (energy and non-energy inputs) and multiple outputs (desirable and undesirable outputs) in the production process. Secondly, as Mandal and Madheswaran (2009) indicated that DEA can also accommodate the objectives of decision making units (DMUs) in assessing energy efficiency ${ }^{4}$.

For this aim, using $\mathrm{CO}_{2}$ emission as an undesirable output, I measure the environmental efficiency scores of countries using the Bad Output model proposed by Tone.

\footnotetext{
${ }^{4}$ These advantages have led to a wide application of DEA tools in the broad area of energy and environmental analysis in recent energy economics literature. For example, on the microeconomic level, WeymanJones (1991), Bagdadioglu et al. (1996), Onut and Soner (2006), Azadeh et al (2007, 2008) and Mukherjee (2008), examined the energy efficiency of different sectors by using industrial data. On the macroeconomic level $\mathrm{Hu}$ and Wang (2006), Hu and Kao (2007), Chien and Hu (2007) and Xu and Liang (2007) examined the total energy efficiency and productivity of regions or countries by using DEA models. In recent years, the concept of environmental DEA technology has become popular, e.g., Färe et al. (1989, 1996), Tyteca (1997), Chung et al. (1997), Zofio and Prieto (2001), Yu (2004), Zaim (2004), Färe and Grosskopf (2004), Zhou and Ang (2008), Zhou et al. (2008a, 2008b), Yang (2010).
} 
But modelling the factors behind these inefficiencies is the subject of another paper. The remainder of the paper is organized as follows: Section 2 introduces the nonoriented BadOutput model under constant return to scale (CRS) assumption (BadOutput-CRS). Section 3 shows sample selection, inputs and outputs. Prior to the conclusion, Section 4 presents the main findings and analyzes the results.

\section{Methodology}

DEA is a nonparametric method for estimating the efficiency ranging between zero and unity in a given set of DMUs such as business firms, as well as government and non-profit agencies and identifying the sources and amounts of inefficiency in each input and output for every DMU.

The intellectual roots of DEA in economics can be traced back to the early 1950s. In literature it was first introduced by Debreau (1951), Koopmans (1951), and Farrell (1957), where two measures of performance, productivity and efficiency, are widely used. Efficiency is a normative measure and is defined as the ratio of the optimal input bundle to the actual input bundle or as the ratio of the actual output to the optimal output. The definition of the optimal depends on the objective of the DMU. Productivity is a descriptive measure of performance and is defined as the ratio of observed output to input. When multiple inputs and/or multiple outputs are involved, one must take the ratios of the quantity indexes of the output and input quantities to obtain a measure of multi-factor productivity. Single-factor productivity measures such as the ratio of output to labour can also be used to evaluate the performance of any particular input. It is worth noting that the traditional measure of energy efficiency based on energy intensity is a measure of single-factor productivity, since it is measured simply by the ratio of output to energy (Cooper et al., 1999; Mukherjee, 2008).

As mentioned before, energy usage also results in undesirable by-products, such as $\mathrm{CO}_{2}$ emissions. Ignoring undesirable outputs may cause misleading results. Thus, development of technologies with less undesirable outputs is an important subject of concern in every production area. DEA usually assumes that the criterion of efficiency is to produce more outputs relative to fewer input resources. Notwithstanding the presence of undesirable outputs, technologies with more desirable outputs and less undesirable outputs relative to less input resources should be recognized as being energy efficient.

Within the non-parametric approach, Charnes, Cooper, and Rhodes (CCR) (1978) first developed DEA to measure the efficiency of individual DMUs in producing multiple outputs from multiple inputs. The original CCR model was applicable only to technologies characterized by CRS. Banker, Charnes and Cooper (BCC) (1984) extended the CCR model to accommodate technologies that exhibit variable returns to scale. In fact, various extensions of these first models, some of which are based on adjustments of conventional measures of efficiency in an environmental efficiency measurement, have been proposed $^{5}$ in the DEA literature. The usual procedures for

\footnotetext{
${ }^{5}$ See Cooper et al., (1999) for details.
}

applying DEA to measure environmental efficiency are to incorporate undesirable outputs in the conventional DEA framework. Despite widespread recognition that researchers should credit DMUs for their provision of desirable outputs, and penalize them for their provision of undesirable outputs, no agreement has been made as to how to incorporate undesirable outputs into an efficiency model (Yang, 2010).

All DEA models could be classified into three types: (1) Radial, (2) Non-Radial and Oriented, and (3) Non-Radial and Non-Oriented. The radial approaches have one general problem, i.e., the neglect of slacks (the input excesses and the output shortfalls). 'Radial' means that a proportionate change of input/output values is the main concern and hence it neglects the existence of slacks as secondary or freely disposable. 'Non-Radial' deals with slacks directly and does not stick to a proportionate change of input/output. Tone (2001) has developed the non-radial slack-based measures (SBM) of efficiency. I aim to measure the efficiency of countries at the economywide level in this paper. That's why it is necessary to take slacks into account owing to some following features of SBM models: First, a scalar measure deals with the slacks of DMUs that are directly concerned. Second, the model is unit invariant and monotone reducing with regard to the slacks. Third, this measure is determined only by consulting the reference-set of the DMUs, and it is not affected by statistics encompassing the whole data set. Fourth, the new measure is very important in dealing with negative outputs while evaluating the efficiency. Fifth, the new measure is closely related to the other measures proposed so far, e.g., the CCR and BCC (Lo and Lu, 2009).

Envelope models could be also 'Oriented' (input, output) or 'Non-Oriented'. Input oriented models aim to reduce the input amounts by as much as possible, while keeping at least the present output levels. Output oriented models maximize output level under the most present input consumption. There is a third choice: 'NonOriented' models (Cooper, et. al, 1999). I use the nonoriented model because it deals with input reduction and output expansion at the same time. In the related literature, most studies follow the original characterization of DEA technology by assuming that the production technology exhibits CRS. Because the scale diversity of countries is relatively small in the OECD sample, I assume CRS.

The model chosen in this paper, namely the Bad Output model proposed by Tone (2001), is non-radial and nonoriented, and utilizes input and output slacks directly in producing an efficiency measure under CRS. The Bad Output model deals with desirable and undesirable outputs independently. The detail of this model can be seen in Appendix A.

\section{Data}

This paper uses DEA to form an efficiency frontier for each of the 23 economies ${ }^{6}$ in each year between 1995 and 2009. The macroeconomic technical efficiency is measured in each economy to determine how far away they are from their efficiency frontier in that year.

\footnotetext{
${ }^{6}$ Belgium, Luxembourg, Hungary, the Czech Republic, Slovakia, Denmark and Island are excluded because of data problems.
} 
Labour and capital are two major inputs in production. Gross domestic product (GDP) is commonly used in measuring a country's overall output ${ }^{7}$. Many theoretical papers and empirical research in the literature conclude that it is appropriate to employ energy as an input in production analysis. In this paper, all inputs (energy, labour and capital) are treated the same way, which means that all inputs could be reduced without reducing desirable output levels. But, as previously mentioned, energy usage also results in the generation of some undesirable outputs, such as $\mathrm{CO}_{2}$ emissions, as by-products of producing desirable output-GDP. Undesirable output is also taken into account in this paper.

Following the practice in macroeconomic efficiency analysis, I employ capital stock (in millions of constant 2000 US dollars) and labour (in million) as non-energy inputs. The main primary energy consumption involves oil, natural gas, coal, nuclear energy and hydropower. I use energy inputs not only separately, shown in Xu and Liang (2007), but also as one input which is namely, primary energy consumption. In this regard, oil and natural gas consumption (in million tons of oil equivalent-Mtoe) are incorporated as one input. Nuclear power and hydropower (Mtoe) are also incorporated as another input. The third input is coal (Mtoe). I don't use the other renewable energy consumption as an input, because some countries in my sample either don't use this type of energy at all or use it in a negligible quantity. I employ GDP (in millions of constant 2000 US dollars) as the desirable output and $\mathrm{CO}_{2}$ emissions (in million tonnes) as the undesirable output. The energy consumption and $\mathrm{CO}_{2}$ emissions of OECD countries are obtained from the BP Statistical Review of World Energy. The data on employee, GDP and gross fixed capital formation are collected from OECD, the World Bank Development Indicator and the Penn World Table.

To our knowledge, data of recent capital stock (after 2000) is not available in any statistical yearbook or database. It is particularly worth noting that economists have often used capital formation synonymously with gross fixed capital formation, but Hubbard (1998) and Kamps (2006) indicated that investment might be a proxy for the corresponding capital stock. In this paper, so as to overcome the shortage of data, I have made several attempts to compute the gross capital stock data. However, these calculations should only be considered as a proxy variable. The depreciation rate is set to be $6 \%$ according to the suggestions in many relevant studies (Hall and Jones, 1999). In this regard, two proxies for physical capital stocks are constructed using the perpetual inventory method. In the perpetual inventory method, the knowledge of initial capital stock is important. Two initial capital stock proxies are used. Firstly, I calculate that the initial capital stock following Hall and Jones $(1999)^{8}$. Due to the

\footnotetext{
${ }^{7}$ For example, Färe et al. (1994) analysed the productivity growth of OECD countries considering labour and capital as inputs and GDP as an output. Chang and Luh (1999) adopted similar inputs and outputs to analyse the productivity growth of 10 Asian economies.

${ }^{8}$ See more details Hall and Jones (1999). The average geometric growth rate for the investment series between the first year with available data and last year is obtained by using semi-log regression. Investments that are used to calculate initial capital stock are likely to be affected by shocks. Therefore, it is appropriate to use three or five-year average of investments (the five-year average is used only for Turkey due to the crisis in Turkey in 1994).
}

fact that there are regular data on gross fixed capital formation (which is also used for initial capital stock) after 1994 in OECD countries, I have selected 1994 as the initial year. After calculating initial capital stock for 1994, I calculate gross capital stock data using the perpetual inventory method for the period 1995-2009. Secondly, the capital stock is also calculated with the initial values obtained from the Penn World Table. Because the capital stock data ends in 1992 in the Penn World Table database, that year is accepted as initial capital stock of countries ${ }^{9}$. In this measure, initial capital stock that is 1985 constant international dollars is transformed into the official exchange rate by PPP conversion factor to the official exchange rate ratio obtained from the World Development Indicator. It is then transformed into constant 2000 US dollars by GDP deflators from the International Monetary Fund World Economic Outlook database as Chien and $\mathrm{Hu}$ (2007) did. Using this initial capital stock, I calculate gross capital stock data by the perpetual inventory method for the period 1995-2009.

\section{Results}

In this section, the energy efficiency and productivity of 23 OECD countries are examined by using the BadOutput-CRS (non-oriented) model. The efficiency scores obtained by this model can be easily seen in Table 1 and Figure 1. The most important feature of these measures is that I use oil-natural gas, hydropower-nuclear and coal as an energy input separately. Analyzing the results in this way, it is possible to see which energy input is used and to what extent it is used inefficiently. Instead of this analysis -which assumes five inputs in total, three of which are energy inputs and two of which are non energy inputs in the production process-, another analysis is made assuming three inputs, one of which is primary energy consumption and two of which are non-energy inputs in the production process.

The results are shown in Appendix B. The efficiency scores using capital stock taken from the Penn World Table are in the 1992 column. Other columns show the efficiency scores using capital stock which I estimate with 1992 initial capital stock obtained by the perpetual inventory method. Also, I measure efficiency scores using the first proxy of capital stock. As I have a high rank correlation between two results, interpretations are based on the scores obtained from the Penn World Table's initial capital stock ${ }^{10}$.

In Table 1 and Figure 1, fully efficient countries have efficiency score "1.0" in this Bad Output model which incorporates $\mathrm{CO}_{2}$ emission as an undesirable output. I compute the efficiency of OECD countries for one year. So the results of different years for one country are from different reference set. That's why the results of different years cannot be compared.

Ireland, Japan, Norway, Switzerland, the United States and the United Kingdom are found efficient in each year's

\footnotetext{
${ }^{9}$ South Korea and Portugal are exceptions. Because there are capital stock data until 1990 for South Korea and until 1991 for Portugal, 1990 and 1991 are accepted as initial capital stocks of these countries respectively.

${ }^{10}$ Sperman rank correlation between two results are higher than 0.85 in all years.
} 
reference set between 1994 and 2009. Italy and Mexico are efficient in the beginning of the period's reference sets while inefficient at the end of the period's reference sets. However, Sweden and Poland are found efficient in the end of the period's reference sets. The scores of Australia, Canada, Greece, South Korea, New Zealand, Portugal, and Poland in the first years, Spain and Turkey are obtained mostly under 0.50 .

Table 1. Results of BadOutput-CRS (non-oriented)

\begin{tabular}{|c|c|c|c|c|c|c|c|c|c|c|c|c|c|c|c|c|}
\hline & 1992 & 1995 & 1996 & 1997 & 1998 & 1999 & 2000 & 2001 & 2002 & 2003 & 2004 & 2005 & 2006 & 2007 & 2008 & 2009 \\
\hline AUS & 0.46 & 0.46 & 0.46 & 0.44 & 0.46 & 0.46 & 0.45 & 0.44 & 0.43 & 0.41 & 0.41 & 0.41 & 0.40 & 0.39 & 0.43 & 0.44 \\
\hline AUT & 0.66 & 0.73 & 0.70 & 0.71 & 0.79 & 0.76 & 0.75 & 0.71 & 0.67 & 0.63 & 0.64 & 0.62 & 0.64 & 0.64 & 0.66 & 0.67 \\
\hline CAN & 0.31 & 0.39 & 0.39 & 0.40 & 0.41 & 0.41 & 0.40 & 0.41 & 0.39 & 0.37 & 0.38 & 0.38 & 0.37 & 0.36 & 0.38 & 0.39 \\
\hline FIN & 0.40 & 0.47 & 0.45 & 0.48 & 0.55 & 0.57 & 0.58 & 0.59 & 0.55 & 0.48 & 0.53 & 0.59 & 0.55 & 0.57 & 0.62 & 0.58 \\
\hline FRA & 0.68 & 1 & 0.88 & 0.92 & 0.92 & 0.91 & 0.93 & 0.92 & 0.88 & 0.81 & 0.80 & 0.80 & 0.80 & 0.75 & 0.76 & 0.80 \\
\hline DEU & 0.48 & 0.55 & 0.55 & 0.57 & 0.61 & 0.61 & 0.60 & 0.60 & 0.57 & 0.52 & 0.53 & 0.52 & 0.52 & 0.56 & 0.58 & 0.58 \\
\hline GRC & 0.52 & 0.47 & 0.47 & 0.45 & 0.46 & 0.42 & 0.41 & 0.42 & 0.41 & 0.39 & 0.39 & 0.39 & 0.39 & 0.40 & 0.43 & 0.43 \\
\hline IRL & 1 & 1 & 1 & 1 & 1 & 1 & 1 & 1 & 1 & 1 & 1 & 1 & 1 & 1 & 1 & 1 \\
\hline ITA & 1 & 1 & 1 & 1 & 1 & 1 & 1 & 1 & 1 & 0.75 & 0.63 & 0.62 & 0.60 & 0.57 & 0.59 & 0.63 \\
\hline JPN & 1 & 1 & 1 & 1 & 1 & 1 & 1 & 1 & 1 & 1 & 1 & 1 & 1 & 1 & 1 & 1 \\
\hline KOR & 0.28 & 0.33 & 0.32 & 0.28 & 0.28 & 0.28 & 0.28 & 0.28 & 0.28 & 0.27 & 0.27 & 0.27 & 0.28 & 0.28 & 0.29 & 0.30 \\
\hline MEX & 1 & 1 & 1 & 1 & 1 & 1 & 1 & 1 & 1 & 0.46 & 1 & 0.44 & 0.41 & 0.40 & 0.46 & 0.41 \\
\hline NLD & 1 & 0.69 & 0.70 & 1 & 1 & 0.69 & 0.66 & 0.61 & 0.60 & 0.52 & 0.53 & 0.52 & 0.54 & 0.50 & 0.57 & 0.57 \\
\hline NZL & 0.34 & 0.44 & 0.44 & 0.43 & 0.45 & 0.43 & 0.43 & 0.42 & 0.41 & 0.37 & 0.38 & 0.37 & 0.36 & 0.37 & 0.36 & 0.40 \\
\hline NOR & 1 & 1 & 1 & 1 & 1 & 1 & 1 & 1 & 1 & 1 & 1 & 1 & 1 & 1 & 1 & 1 \\
\hline POL & 0.33 & 0.33 & 0.32 & 0.32 & 0.32 & 0.31 & 0.31 & 0.30 & 0.31 & 0.29 & 0.30 & 0.29 & 0.32 & 0.32 & 1 & 1 \\
\hline PRT & 0.62 & 0.55 & 0.56 & 0.53 & 0.51 & 0.47 & 0.43 & 0.45 & 0.40 & 0.38 & 0.38 & 0.37 & 0.37 & 0.37 & 0.40 & 0.40 \\
\hline ESP & 0.47 & 0.52 & 0.53 & 0.51 & 0.53 & 0.49 & 0.47 & 0.49 & 0.44 & 0.42 & 0.41 & 0.40 & 0.40 & 0.38 & 0.42 & 0.48 \\
\hline SWE & 0.63 & 0.75 & 0.70 & 0.74 & 0.80 & 1 & 1 & 1 & 1 & 1 & 1 & 1 & 1 & 1 & 1 & 1 \\
\hline CHE & 1 & 1 & 1 & 1 & 1 & 1 & 1 & 1 & 1 & 1 & 1 & 1 & 1 & 1 & 1 & 1 \\
\hline TUR & 0.37 & 1 & 0.41 & 0.39 & 0.38 & 0.35 & 0.34 & 0.32 & 0.32 & 0.31 & 0.33 & 0.40 & 0.39 & 0.36 & 0.36 & 0.35 \\
\hline USA & 1 & 1 & 1 & 1 & 1 & 1 & 1 & 1 & 1 & 1 & 1 & 1 & 1 & 1 & 1 & 1 \\
\hline GBR & 1 & 1 & 1 & 1 & 1 & 1 & 1 & 1 & 1 & 1 & 1 & 1 & 1 & 1 & 1 & 1 \\
\hline
\end{tabular}
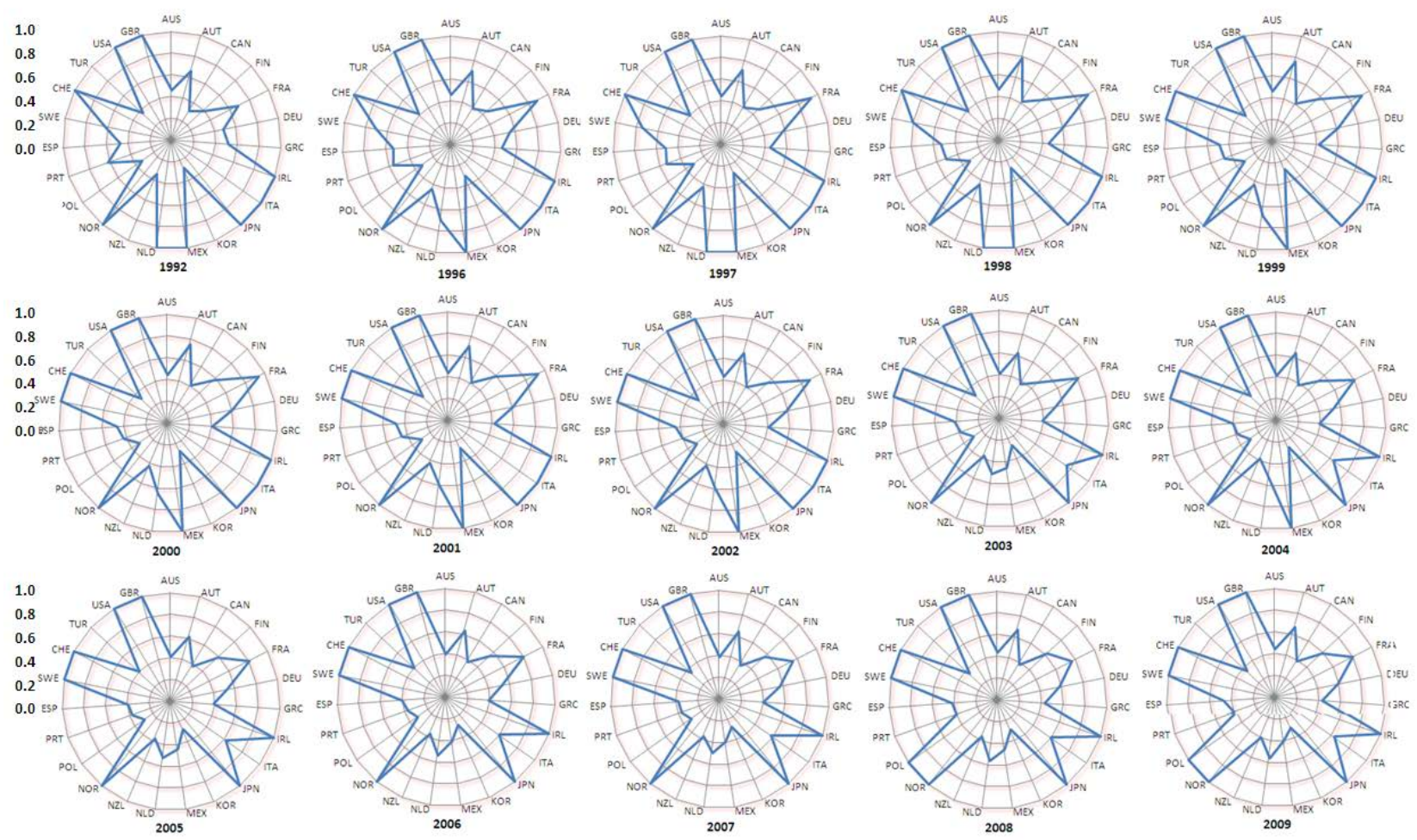

Figure 1. Radar Graphs of BadOutput-CRS (non-oriented) Models 
The reason why some countries are inefficient is that they produce less with present input consumption, but need to produce more compared to efficient countries. This model then shows which inputs are used inefficiently. When examining the projections of the model in terms of labour, we see that especially Poland, Turkey, Mexico in some years, Portugal, South Korea and New Zealand use this input very inefficiently. What does such inefficiency in labour mean? The low level of output produced by this number of employees implies the use of unskilled labour as well as the informal economy ${ }^{11}$.

Oil and natural gas are still basic inputs for all countries. According to the results of the model, especially Canada, Mexico in some years, South Korea, Netherlands in some years and New Zealand do not use these inputs efficiently compared to other countries. Hydropower and nuclear power are inputs that countries use at different rates. The projections of the model for these terms show that especially South Korea, Canada, New Zealand, Portugal, Spain, Turkey and Mexico use these inputs highly inefficiently. Except for Canada, South Korea and Spain the reason for requiring such a reduction in this input can be explained because of putting it in the model as an incorporated variable. The reason why I incorporate this variable in this way is that nuclear power is not used as an input in most countries. Therefore, this variable enters the model in such a way that countries produce GDP using both these inputs (hydropower and nuclear power) even though some of them do not even use one of them. In addition, it is particularly noticeable that Poland, Australia, South Korea, Turkey and Greece do not use coal efficiently compared to the other countries.

When examining the results in terms of $\mathrm{CO}_{2}$ emissions, it can be seen that inefficient countries produce an amount of desirable output with high $\mathrm{CO}_{2}$ emissions. In this respect, especially Poland, South Korea, Canada, Australia, Turkey, Mexico in some years, Greece, New Zealand and Netherlands can produce the same amount of GDP with less $\mathrm{CO}_{2}$ emissions compared to other benchmarking countries. But the correct interpretation would not be that these inefficient countries pollute the environment more. It is true that increases in $\mathrm{CO}_{2}$ emissions of the countries reduce their efficiency, but these countries are also inefficient, especially regarding energy and labour use.

It is also important to determine the reasons for these inefficiencies in these countries. In accordance with this objective, a model for technical inefficiency effect in a stochastic frontier production function is used in the related literature and the factors that cause inefficiencies of countries are determined. For example, Batesse and Coelli (1995) suggested this kind of model. In this paper, I didn't develop the paper in that way. Future research should explain the reasons for inefficiencies of countries and should examine technical inefficiency effects and the factors that cause inefficiencies.

\section{Conclusion}

Forecasting and tracking economy-wide energy efficiency trends have gained importance at the national

\footnotetext{
${ }^{11}$ The projections of the model are not explained in terms of capital stock because it is only used as a proxy variable.
}

and local levels of government due to the realisation that energy efficiency is a cost effective way of addressing the wide-ranging problems associated with the changing global energy scene, climate change and economic competition. I have presented an overview of the energy efficiency of the 23 OECD countries in the time period 1995-2009. I have used the DEA method to estimate the technical efficiency for these countries. The traditional carbon intensity indicator is too simple to capture the multidimensional features of the development of an economy. DEA efficiency measures, integrated with the concept of environmental DEA technology, have gained popularity in environmental performance measurement. A common feature of previous DEA-related energy efficiency studies is that energy consumption is modelled as an input within a production framework, without considering undesirable outputs. But, in the real world, energy usage results in the generation of undesirable outputs as by-products of desirable outputs. So, two outputs (real GDP and $\mathrm{CO}_{2}$ emissions) and five inputs (labour, real capital stock, oil+natural gas consumption, hydropower+nuclear consumption, and coal consumption) are taken into the DEA model. However, it is necessary to mention that the results will be sensitive to the sample. These measurements serve not just as monitoring tools, but also as a basis for energy efficiency policies and regulations aimed to achieve greater energy conservation, and pollution abatement measures.

In this paper I only measure of the efficiencies of countries. But determining the factors that cause inefficiencies is also important. By doing this we can see the structural differences between countries because structural differences between countries can be taken into account in assessment and comparison of energy efficiency levels. In some countries, industrialisation, urbanisation, transport services, infrastructure development and lifestyle changes require more energy and lead to a sort of inefficiency. It is suggested in our results that the environmental efficiency measurement yields much lower results in all countries. There has already been an energy shortage in many parts of the countries, which has forced a large number of factories to produce under capacity, or even to close completely. Energy restrictions aiming to reduce $\mathrm{CO}_{2}$ emissions are likely to exacerbate the energy shortage problem and cost both income and employment. Our results do not mean that the more efficient countries can ignore the Kyoto Protocol, because the efficiency scores that have been found by this analysis are obtained by comparing the countries in the sample.

Numerous technologies and concepts for efficiency improvements have been developed for the policy agendas of organizations. But as argued by Geller et al. (2006) in detail, it can be deduced from the vast experience with policies and programs aimed to increase energy efficiency that energy efficiency policies and programs give the best results if they are integrated into market transformation strategies, addressing the range of barriers. For an economy to improve its environmental efficiency, fuel choice is very important. By substituting fossil fuels with renewable energy, an economy's environmental efficiency can be significantly improved. Economic development always remains a crucial goal for some countries, but, it remains important to achieve this goal in a sustainable 
way. Energy efficiency and renewable energy can help these countries to both maintain and increase their economic development rates without depleting the limited fuel reserves any further or harming either the environment or human health.

\section{References}

[1] Ang, B.W. (2006) 'Monitoring changes in economy-wide energy efficiency: from energy-GDP ratio to composite efficiency index', Energy Policy, Vol. 34, pp.574-582.

[2] Azadeh, A., Amalnick, M. S., Ghaderi, S. F. and Asadzadeh, S. M. (2007) 'An integrated DEA PCA numerical taxonomy approach for energy efficiency assessment and consumption optimization in energy intensive manufacturing sectors', Energy Policy, Vol. 35, pp. 3792-3806.

[3] Azadeh, A., Ghaderi, S. F. and Asadzadeh, S. M. (2008), 'Energy efficiency modeling and estimation in petroleum refining industry - a comparison using physical data', Paper presented at the International Conference on Renewable Energies and Power Quality (ICREPQ'11), Santander, 12-14 March 2008.

[4] Bagdadioglu, N., Price, C. M. W. and Weyman-Jones, T. G. (1996) 'Efficiency and ownership in electricity distribution: a non parametric model of the Turkish experience', Energy Economics, Vol. 18, pp.1-23.

[5] Banker, R. D., Charnes, R. F. and Cooper, W. W. (1984), 'Some models for estimating technical and scale inefficiencies in data envelopment analysis', Management Science, Vol. 30, pp.10781092.

[6] Battese, G.E. and Coelli, T.J. (1995), 'A model for technical inefficiency effects in a stochastic frontier production function for panel data', Empirical Economics, Vol. 20, pp.325-332.

[7] Bosseboeuf, D., Chateau, B., and Lapillonne, B. (1997), 'Crosscountry comparison on energy efficiency indicators: the on-going European effort towards a common methodology', Energy Policy, Vol. 25, pp.673-682.

[8] Chang, C. C. and Luh, Y. H. (1999), 'Efficiency change and growth in productivity: the Asian growth experience', Journal of Asian Economics, Vol. 10, pp.551-570.

[9] Charnes, A., Cooper, W. W. and Rhodes, E. (1978), 'Measuring the efficiency of decision making units', European Journal of Operational Research, Vol. 3, pp.392-444.

[10] Chien, T. and Hu, J. L. (2007), 'Renewable energy and macroeconomic efficiency of OECD and non-OECD economies', Energy Policy, Vol. 35, pp.3606-3615.

[11] Chung, Y.H., Färe, R. and Grosskopf, S. (1997), 'Productivity and undesirable outputs: a directional distance function approach', Journal of Environmental Management, Vol. 51, pp.229-240.

[12] Cooper, W. W., Seiford, L. M. and Tone, K. (1999), Data Envelopment Analysis: A Comprehensive Text with Models, Applications, References and DEA-Solver Software, Kluwer Academic Publishers, Hingham, MA, USA.

[13] Debreau, G. (1951), 'The coefficient of resource utilization', Econometrica. Vol. 19, pp.273-290.

[14] Duro, J. A., Alcántara, V. and Padilla, E. (2010), 'International inequality in energy intensity levels and the role of production composition and nergy efficiency: an analysis of OECD countries', Ecological Economics, Vol. 69, pp.2468-2474.

[15] Färe R., Grosskopf, S., Norris, M. and Zhang, Z. (1994), 'Productivity growth, technical progress, and efficiency change in industrialized countries', American Economic Review. Vol. 84, pp.66-83.

[16] Färe, R. and Grosskopf, S. (2004), 'Modeling undesirable factors in efficiency evaluation: comment', European Journal of Operational Research, Vol. 157, pp.242-245.

[17] Färe, R., Grosskopf, S. and Tyteca, D. (1996), 'An activity analysis model of the environmental performance of firmsapplication to fosil fuel-fired electric utilities', Ecological Economics, Vol. 18, pp.161-175.

[18] Färe, R., Grosskopf, S., Lovell, C. A. K. and Pasurka, C. (1989), 'Multilateral productivity comparisons when some outputs are undesirable: a nonparametric approach', The Review of Economics and Statistics, Vol. 71, pp.90-98.

[19] Farrell, M. J. (1957), 'The measurement of productive efficiency', Journal of the Royal Statistical Society, Vol. 120, pp.253-290.
[20] Freeman, S. L., Niefer, M. J. and Roop, J. M. (1997), 'Measuring industrial energy intensity: practical issues and problems', Energy Policy, Vol. 25, pp.703-714.

[21] Geller, H., Harrington, P. A., Rosenfeld, H., Tanishima, S. and Unander, F. (2006), 'Policies for increasing energy efficiency: thirty years of experience in OECD countries', Energy Policy, Vol. 34, pp.556-573.

[22] Grösche, P. (2008), 'Measuring residental energy efficiency improvement with DEA', Ruhr Economic Papers 60.

[23] Hall, R. E. and Jones, C. I, (1999), 'Why do some countries produce so much more output per worker than others?', NBER Working Papers, 6564, National Bureau of Economic Research, Inc.

[24] Hu, J. L. and Kao, C. H. (2007), 'Efficient energy-savings targets for APEC economies’, Energy Policy, Vol. 35, pp.373-382.

[25] Hu, J. L. and Wang, S. C. (2006), 'Total-factor energy efficiency of regions in China', EnergyPolicy, Vol. 34, pp.3206-3217.

[26] Hubbard, R. G. (1998), 'Capital market imperfections and investment', Journal of Economic Literature. Vol. 36, pp.193-225.

[27] Kamps, C. (2006), 'New estimates of government net capital stocks for 22 OECD countries 1960-2001’, IMF Staff Papers 53.

[28] Koopmans, T. C. (1951), 'An analysis of production as an efficient combination of activities', in Koopmans, T. C. (Ed.): Activity Analysis of Production and Allocation, Proceeding of a Conference, pp.33-97, John Wiley and Sons Inc., London.

[29] Lo, S. F. and Lu, W. M. (2009), 'An integrated performance evaluation of financial holding companies in Taiwan', European Journal of Operational Research, Vol.198, pp.341-350.

[30] Mandal, S. K. and Madheswaran, S. (2009), 'Efficiency in presence of undesirable output: an application of data envelopment analysis (DEA) to Indian cement industry', Institute for Social and Economic Change (ISEC) Working Paper no. 235.

[31] Mukherjee, K. (2008), 'Energy use efficiency in U.S. manufacturing: a nonparametric analysis', Energy Economics, Vol. 30, pp.76-96.

[32] Onut, S. and Soner, S. (2006), 'Energy efficiency assessment for the Antalya region hotels in Turkey', Energy and Buildings, Vol.38, pp.964-971.

[33] Patterson, M. G. (1996), 'What is energy efficiency? concepts, indicators and methodological issues', Energy Policy, Vol. 24, pp.377-390.

[34] Phylipsen, G. J. M. (Dian), Blok, K. and Bode, J.W. (2002), 'Industrial energy efficiency in the climate change debate: comparing the US and major developing countries', Energy for Sustainable Development, Vol.6, pp.30-44.

[35] Price, L., Phylipsen, G. J. M. and Worrell, E. (2000a), Energy Use and Carbon Dioxide Emissions in the Steel Sector in Key Developing Countries: Preliminary Sector Analysis, Lawrence Berkeley National Laboratory.

[36] Price, L., Phylipsen, G. J. M. and Worrell, E. (2000b), Energy Use and Carbon Dioxide Emissions in the Cement Sector in Key Developing Countries: Preliminary Sector Analysis, Lawrence Berkeley National Laboratory.

[37] Reddy, B. S. and Ray, B. K. (2010), 'Decomposition of energy consumption and energy Intensity in Indian manufacturing industries', Energy for Sustainable Development, Vol. 14, pp.3547.

[38] Stern, N. (2007), The Economics of Climate Change: The Stern Review, Cambridge University Press, Cambridge.

[39] Tone, K. (2001), 'A slacks-based measure of efficiency in data envelopment analysis', European Journal of Operational Research, Vol. 130, pp.498-509.

[40] Tyteca, D. (1997), 'Linear programming models for the measurement of environmental performance of firms - concepts and empirical results', Journal of Productivity Analysis, Vol. 8, pp.183-197.

[41] Xu, X. P. and Liang, L. (2007), 'Energy efficiency and productivity of China: compared with other countries', in Shi, Y., van Albada, G.D. and Dongarra, J. (Ed): Computational ScienceICCS 2007, 7th International Conference Part III, Beijing, pp.988-991, China, May 27-30,

[42] Yang, H. (2010), Carbon Reduction Potential, and Economic Development in the People's Republic of China, A Total Factor Production Model, Asian Development Bank, Philippines.

[43] Zaim, O. (2004), 'Measuring environmental performance of state manufacturing through changes in pollution intensities: a DEA framework', Ecological Economics, Vol. 48, pp.37-47. 
[44] Zhou, P. and Ang, B. W. (2008), 'Linear programming models for measuring economy-wide energy efficiency performance', Energy Policy, Vol. 36, pp.2911-2916.

[45] Zhou, P., Ang, B. W. and Poh, K. L. (2008a), 'A survey of data envelopment analysis in energy and environmental studies', European Journal of Operational Research, Vol. 189, pp.1-18.

[46] Zhou, P., Ang, B. W. and Poh, K. L. (2008b), 'Measuring environmental performance under different environmental DEA technologies', Energy Economics, Vol. 30, pp.1-14.

[47] Zofio, J. L. and Prieto, A. M. (2001), 'Environmental efficiency and regulatory standards: the case of $\mathrm{CO}_{2}$ emissions from OECD industries', Resource and Energy Economics, Vol. 23, pp.63-83.

\section{Appendix A: Bad Output-CRS Model (non-oriented)}

The Bad Output model applies a SBM of efficiency in Tone (2001). This SBM of efficiency, namely the Bad Output model, is also non-radial and non-oriented, and utilizes input and output slacks directly in producing an efficiency measure. For the Bad Output model, it is necessary to decompose the output matrix $Y$ into $\left(Y^{d}, Y^{u d}\right)$ where $Y^{d}$ and $Y^{u d}$ denote desirable and undesirable output matr ices, respectively. For a DMU $\left(x_{0}, y_{0}\right)$, the decomposition is denoted as $\left(x_{0}, y_{0}^{d}, y_{0}^{u d}\right)$. The PPS is defined as:

$$
P=\left\{\begin{array}{l}
\left(x, y^{d}, y^{u d}\right) \mid x \geq X \lambda, y^{d} \leq Y^{d} \lambda, \\
y^{u d} \geq Y^{u d} \lambda, L \leq e \lambda \leq U, \lambda \geq 0
\end{array}\right\}
$$

In the equation, $\lambda$ is the intensity vector, and $L$ and $U$ are the lower and upper bounds of the intensity vector respectively. The efficiency status is defined as follows. A DMU $\left(x_{0}, y_{0}^{d}, y_{0}^{u d}\right)$ is efficient in the presence of undesirable outputs, if there is no vector $\left(x, y^{d}, y^{u d}\right) \in P$ such that $x_{0} \geq 0, y_{0}^{d} \leq y^{d}, y_{0}^{u d} \geq y^{u d}$ with at least one strict inequality. According to this definition, SBM of efficiency in Tone (2001) is modified as:

$$
\begin{gathered}
\rho^{\rightarrow}=\frac{\min \left(1-\frac{1}{m} \sum_{i=1}^{m} \frac{S_{i 0}^{-}}{x_{i 0}}\right)}{1+\frac{1}{S}\left(\sum_{r=1}^{S_{1}} \frac{S_{r}^{d}}{y_{r 0}^{d}}+\sum_{r=1}^{S_{2}} \frac{S_{r}^{u d}}{y_{r 0}^{u d}}\right)} \\
\text { subject to } x_{0}=X \lambda+S^{-} \\
y_{0}^{d}=Y \lambda-S^{d} \\
y_{0}^{u d}=Y \lambda+S^{u d} \\
L \leq e \lambda \leq U \\
S^{-}, S^{d}, S^{u d}, \lambda \geq 0
\end{gathered}
$$

The vectors $S^{-}$and $S^{u d}$ denote excesses in inputs and undesirable outputs, respectively, while $S^{d}$ shows shortages in desirable outputs. $S_{1}$ and $S_{2}$ denote the number of elements in $S^{u d}$ and $S^{d}$, and $S=S_{1}+S_{2}$. If an optimal solution of this program is $\left(【 \rho \coprod^{\rightarrow}, S^{-\rightarrow}, S^{d^{*}}, S^{u d^{*}}\right)$, then we can demonstrate that the $\operatorname{DMU}\left(x_{0}, y_{0}^{d}, y_{0}^{u d}\right)$ is efficient in the presence of undesirable outputs, if only $\rho^{\rightarrow}=1$ i.e., $S^{-\rightarrow}=0, S^{d \rightarrow}=0, S^{u d \rightarrow}=0$. If the DMU is inefficient, i.e., $\rho \rightarrow<1$ we can improve and make it efficient by deleting the excesses in inputs and undesirable outputs and augmenting the shortfalls in desirable outputs by the following projection:

$$
\begin{aligned}
& x_{0} \Leftarrow x_{0}-S^{-\rightarrow} \\
& y_{0}^{d} \Leftarrow y_{0}^{d}+S^{d \rightarrow} \\
& y_{0}^{u d} \Leftarrow y_{0}^{u d}-S^{u d \rightarrow}
\end{aligned}
$$

The above fractional program can be transformed into an equivalent linear program by using Charnes -Cooper transformation $^{12}$. Considering the dual side of the linear program, the following dual program in the variable $v, u^{d}, u^{u d}$ for the CRS case, i.e. $\mathrm{L}=0, \mathrm{U}=\infty$ can be demonstrated $^{13}$ :

$$
\max u^{d} y^{d}-v x_{0}-u^{u d} y_{0}^{u d}
$$

subject to

$$
\begin{gathered}
u^{d} Y^{d}-v X-u^{u d} Y^{u d} \leq 0 \\
v \geq \frac{1}{m}\left[\frac{1}{x_{0}}\right] \\
u^{d} \geq \frac{1+u^{d} y_{0}^{d}-v x_{0}-u^{u d} y_{0}^{u d}}{S}\left[\frac{1}{y_{0}^{d}}\right] \\
u^{u d} \geq \frac{1+u^{d} y_{0}^{d}-v x_{0}-u^{u d} y_{0}^{u d}}{S}\left[\frac{1}{y_{0}^{u d}}\right]
\end{gathered}
$$

We can interpret the dual variables $v$ and $u^{u d}$ as the virtual prices (costs) of inputs and undesirable outputs, respectively, while $u^{d}$ denotes the price of desirable outputs. The aim of the dual program is to obtain the optimal virtual costs and prices for the DMU so that the profit $u^{d} y^{d}-v x-u^{u d} y^{u d}$ does not exceed zero for every DMU and maximizes the profit $u^{d} y_{0}^{d}-v x_{0}-u^{u d} y_{0}^{u d}$ for the DMU concerned. Apparently, the optimal profit is at best zero which identifies the DMU as efficient.

\footnotetext{
${ }^{12}$ See Tone (2001) for details.

${ }^{13}$ Refer to Tone (2001) for derivation.
} 
Appendix B: Results of BadOutput-CRS (non-oriented) (Energy input is primary energy consumption)

\begin{tabular}{|c|c|c|c|c|c|c|c|c|c|c|c|c|c|c|c|}
\hline & 1995 & 1996 & 1997 & 1998 & 1999 & 2000 & 2001 & 2002 & 2003 & 2004 & 2005 & 2006 & 2007 & 2008 & 2009 \\
\hline AUS & 0.52 & 0.53 & 0.54 & 0.56 & 0.56 & 0.55 & 0.55 & 0.53 & 0.52 & 0.52 & 0.52 & 0.51 & 0.50 & 0.53 & 0.55 \\
\hline AUT & 0.70 & 0.70 & 0.71 & 0.75 & 0.78 & 0.80 & 0.77 & 0.76 & 0.70 & 0.72 & 0.70 & 0.71 & 0.72 & 0.74 & 0.73 \\
\hline CAN & 0.48 & 0.49 & 0.49 & 0.51 & 0.51 & 0.51 & 0.52 & 0.50 & 0.48 & 0.49 & 0.49 & 0.49 & 0.48 & 0.50 & 0.52 \\
\hline FIN & 0.52 & 0.53 & 0.56 & 0.62 & 0.64 & 0.66 & 0.67 & 0.64 & 0.59 & 0.64 & 0.71 & 0.68 & 0.70 & 0.76 & 0.71 \\
\hline FRA & 0.81 & 1 & 0.84 & 0.87 & 0.90 & 0.92 & 0.91 & 0.88 & 0.82 & 0.82 & 0.82 & 0.82 & 0.80 & 0.81 & 0.82 \\
\hline DEU & 0.59 & 0.59 & 0.61 & 0.65 & 0.68 & 0.69 & 0.69 & 0.69 & 0.65 & 0.66 & 0.66 & 0.66 & 0.66 & 0.68 & 0.68 \\
\hline GRC & 0.55 & 0.55 & 0.54 & 0.54 & 0.52 & 0.50 & 0.52 & 0.50 & 0.51 & 0.51 & 0.51 & 0.52 & 0.52 & 0.55 & 0.57 \\
\hline IRL & 1 & 1 & 1 & 1 & 1 & 1 & 1 & 1 & 1 & 1 & 1 & 1 & 1 & 1 & 1 \\
\hline ITA & 1 & 1 & 1 & 1 & 1 & 1 & 1 & 1 & 1 & 0.70 & 0.69 & 0.68 & 0.67 & 0.67 & 0.67 \\
\hline JPN & 1 & 1 & 1 & 1 & 1 & 1 & 1 & 1 & 1 & 1 & 1 & 1 & 1 & 1 & 1 \\
\hline KOR & 0.38 & 0.38 & 0.35 & 0.35 & 0.35 & 0.35 & 0.36 & 0.36 & 0.35 & 0.36 & 0.37 & 0.38 & 0.38 & 0.40 & 0.41 \\
\hline MEX & 1 & 1 & 1 & 1 & 0 & 0 & 0 & 0 & 0 & 0.44 & 0 & 0.44 & 0.43 & 0.44 & 0.42 \\
\hline NLD & 1 & 0.60 & 0.61 & 1 & 1 & 0.62 & 0.62 & 0.58 & 0.55 & 0.56 & 0.56 & 0.56 & 0.56 & 0.60 & 0.60 \\
\hline NZL & 0.46 & 0.47 & 0.44 & 0.45 & 0.46 & 0.44 & 0.45 & 0.44 & 0.44 & 0.44 & 0.45 & 0.44 & 0.44 & 0.45 & 0.48 \\
\hline NOR & 1 & 1 & 1 & 1 & 1 & 1 & 1 & 1 & 1 & 1 & 1 & 1 & 1 & 1 & 1 \\
\hline POL & 0.32 & 0.32 & 0.32 & 0.33 & 0.32 & 0.32 & 0.32 & 0.32 & 0.32 & 0.33 & 0.34 & 0.34 & 0.35 & 0.36 & 0 \\
\hline PRT & 0.61 & 0.62 & 0.59 & 0.57 & 0.54 & 0.51 & 0.52 & 0.48 & 0.46 & 0.46 & 0.45 & 0.45 & 0.45 & 0.49 & 0.49 \\
\hline ESP & 0.59 & 0.59 & 0.58 & 0.60 & 0.59 & 0.57 & 0.58 & 0.54 & 0.51 & 0.50 & 0.49 & 0.50 & 0.49 & 0.52 & 0.53 \\
\hline SWE & 0.67 & 0.67 & 0.72 & 0.83 & 0.92 & 1 & 1 & 1 & 1 & 1 & 1 & 1 & 1 & 1 & 1 \\
\hline CHE & 1 & 1 & 1 & 1 & 1 & 1 & 1 & 1 & 1 & 1 & 1 & 1 & 1 & 1 & 1 \\
\hline TUR & 1.00 & 0 & 0.48 & 0.47 & 0.43 & 0.42 & 0.42 & 0.42 & 0.41 & 0.44 & 0.46 & 0.46 & 0.44 & 0.44 & 0.43 \\
\hline USA & 1 & 1 & 1 & 1 & 1 & 1 & 1 & 1 & 1 & 1 & 1 & 1 & 1 & 1 & 1 \\
\hline GBR & 1 & 1 & 1 & 1 & 1 & 1 & 1 & 1 & 1 & 1 & 1 & 1 & 1 & 1 & 1 \\
\hline
\end{tabular}

